\title{
Management of influence of using of fertilizers on soil quality: The case of nitrate pollutants
}

\author{
Layth Nesseef $^{1^{*}}$, Dragan Marković ${ }^{1}$, Dejan Marković ${ }^{1}$, Dragan Jovšić ${ }^{2}$, Zoran Jovanović ${ }^{3}$ \\ ${ }^{1}$ University of Belgrade, Belgrade, Serbia; ${ }^{*}$ Corresponding Author: lakilee@yahoo.com \\ ${ }^{2}$ Agriculture Faculty, University of Belgrade, Belgrade, Serbia \\ ${ }^{3}$ Mechanical Engineer, Belgrade, Serbia
}

Received 13 September 2013; revised 17 October 2013; accepted 25 October 2013

Copyright (C) 2013 Layth Nesseef et al. This is an open access article distributed under the Creative Commons Attribution License, which permits unrestricted use, distribution, and reproduction in any medium, provided the original work is properly cited.

\begin{abstract}
Contamination of soil and water contributes to the reduction of economic income, and also has an impact on economic development and management organizations and services. In order to avoid excessive use of nitrate fertilizers we made research through systematic laboratory study of applying the basic chemical and physical analyzes of selected soil samples. In this research, we apply the method that was studied movement of nitrate solution in two soil types (sand and loess), since the impact of fertilizers on the environment depends on the soil types and its category. As the result, we got accurate functional dependences of sufficiently step height of soil and the concentration of nitrate ions and those can find a specific application in agriculture for these two types of soil, and may be sufficiently adequate substitution for the field investigations. The aim of the study was to investigate the most important negative environmental and economic consequences of the using of artificial fertilizers and to show that soil tests in the laboratory can be an adequate substitute for a field test because of economic savings. The comparative analysis of experimental and numerical results for nitrates leaching in different soil types were concluded.
\end{abstract}

Keywords: Pollution; Contamination; Ecology; Environment; Soil; Water; Nitrate

\section{INTRODUCTION}

Materials like artificial fertilizers and agents for plant protection, like, i.e. pesticides become polluters when they are in inappropriate time and quantities. Worsening of chemical characteristics of soil becomes worsen by entering and delaying with water damaging salts and other compounds in it. Creating of herbal cover is connected with land conditions, primarily with soil humidity. Change of water regime because of reducing of sub land water, and reducing humidity of upper layer, imply change in life conditions of herbs. The impact of underneath water on herbs productivity is especially strong expressed on sandy and sandy-ilovast soil, with proportionally small capillary potential. Pollution is mostly expressed through degradation of certain kind of natural resources: air, water, soil, as well as the degradation of natural environment in settlements and off them, and some other natural conditions: climate, silence, landscape. These are changes of certain characteristics of life environment that can have bad influence on health, survival and activities of people and other living creators. Therefore, pollution can represent every change of physical environment that can be objectively determined and that is not always seen as harmful effect by subjects. When it is about job costing it is much easier to determine cost of investments for lessening pollution in comparison with determining value of benefits which brings certain lessening in pollution. For this purpose men began to use more and more simulation methods and other methods that allow gradual bringing closer to allowed level of pollution. In certain cases it is also possible and indirectly to define value of harmful effects and costs of reduction in pollution. In certain cases it is also possible and indirectly to establish values of harmful effects and costs of reducing pollution. For example, harmful effects caused by use of artificial fertilizers on environment can be determined on the basis of varying selling price of product, because it is deemed as a factor for guiding to ecological way of production. Problem complexity results from complexity of geological and hidrogeological construction of environment, space and time changeable 
parameters, as a result of hidrogeological processes of complexity of chemical, geochemicall and hidrochemicall characteristics and processes in shoot environment. As every pollution does not have to be seen as harmful effect, so not all effects have to be connected with pollution. From the stand of economic development and economy of environment, we could give some advantages using terms of harmful effects, because it includes wider domain relation between man and environment including subjective and conflict components of this relations.

\section{MOVEMENT OF POLLUTANT MATERIES IN UNSATTURATED ZONE}

Soil analyses are one way to come to lessening lost of nitrogen and lessening concentration of nitrate in soil. Table 1 illustrates how much are the costs analyzed by ha in three countries members of EU. Samples of soil are extracted on three depths $0-30 \mathrm{~cm}, 30-60 \mathrm{~cm}$ and 60 $90 \mathrm{~cm}$ in France and in Germany, while in Holland is extracted only one sample from depth of $0-10 \mathrm{~cm}$.

Unsaturated environment includes soil in which plants are planted, and part of geological base until the level of underneath water, where the pores of particles in unsaturated environment are partially fulfilled with water, and by other part with air. Unsaturated environment is composed from three phases: firm, liquid and gaseous. Firm phase of soil is composed of mineral and organic particles different dimensions. Liquid phase represents water solution of different kind of salts, it is composed of water and dissolute mineral material-salt and gases (this is the case that was here experimentally processed). Gaseous phase is land air. Between this three composed parts exists mutual connection and causality, because change of other part of them causes the change of others. Movement of water in unsaturated environment is caused by changes of climate hydrologic conditions (rainfall, air humidity, temperature, atmospheric pressure, radiation, lasting of sunshine, evaporation, surface flow out) and hidrogeological conditions (infiltration speed, coefficient of hydraulically conducting, thickness of the zone of temporary saturation, depth of laying waterproof layer, soil saturation with water and so on). Factors that influence on physical ("no-reactive") migration (that is the issue of this paper) of pollutant material through unsaturated zone are very much dependent from the characteristics of land. Concretely, relation between humidity of soil, water pressure, saturated and unsaturated coefficient of filtration, dispersivity, sorption and diffusivity of pollutant materials in water and soil is very important for quantifying intensively (speed) of movement of infiltrateing water as well as pollutant materials that are dissolved in it [2]. This represents explanation of experiment. All this mentioned factors have the smallest impact in sand, and that is the reason why the sand was used in work of Al-Darby and Abdel-Nasser [3], and that is why we have taken it and then compared it with loess. Results of our experimental investigation point on differences between speed of movement of pollutant materials expressed because of physical characteristics of samples. Loess has, because the presence of clay, slow the movement of pollutant materials that is different than the influence of sand. Gained results are shown in later part of this paper.

\section{EXPERIMENTAL PART: MATERIALS AND INVESTIGATION METHODS}

Samples used in this investigation originate from collection Minning-geological Faculty. Loess originates from the location of Bezanija, while sand originates from the short of Sava River. First, the aim was to determine minerals presented in mentioned samples. On the sand sample it was conducted recording of complete cut up in small pieces dust, whilst at samples of loess after recorded complete sample, there was determined the presence of mineral of clay. Then we are present to extracting fraction of clay, preparing samples on glass tile and recording with additional treatment, in order to confirm presence of certain minerals of clay. For recording was used x-ray aparatus Philips 1010, and we have conducted $\mathrm{x}$-ray difraction analysis referently oriented preparation of clay. Sample of clay was then exposed to etilenglicol vapor for 24 hours, and then the sample was heating to red on $550^{\circ} \mathrm{C}$ for $30 \mathrm{~min}$, and all was again recorded. Because in this paper, beside economic and ecological aspect, it was justifed that, in order to perceive impact of implementation of mineral fertilizers on underneath water and soil, we do also and additional analasies that will

Table 1. Amount of expenses for analysis of nitrate concentration in soil [1].

\begin{tabular}{cccccc}
\hline State & Considered surface (ha) & $\begin{array}{c}\text { Number of analysis } \\
\text { of soil in one year }\end{array}$ & Frequency soil analysis & $\begin{array}{c}\text { Cost analysis by ha } \\
\text { the yearly basis (EUR) }\end{array}$ & $\begin{array}{c}\text { Point of cover } \\
\text { (kg/ha yearly) }\end{array}$ \\
\hline France & 70 & 18 & 5 years & $10-22$ & 45 \\
Holland & 3 & 1 & 3 years & $8-15$ & 20 \\
Germany & $5-7$ & 15 & yearly & 20 & 40 \\
\hline
\end{tabular}

Remark: There were presented the savings of 0.5 EUR by the kg N (used nitrogen from fertilizers); ${ }^{\text {Point }}$ of cover: Point in which costs and profits are identical. 
include and examination of mineral composition of sand and loess as base, for this presented paper. Implementation of mineral fertilizers in intensive plant production became a measure that is implementing on all contninents, because of lower price, and because the fact that difference in price between natural and artificial fertilizers is not irrelevant. For that reason it is important to determine quantity of necessary fertilizers that are deficient in soil, as well as the way of adding supstrates, once and in more times, if it is needed. Knowing the characteristics of supstrates of base that we treat with mineral fertilizers, is important also and from ecological aspects. Here is primarily needed to know permeability of supstrats for water, because the part of additional nourishment, that are not adopted from the side-part of plants or adsorbed for the particles of supstrate, gets through washing out and can come in underland water, and that is from ecological aspects harmfull and prohibited. From above mentioned we can understand the importance of determining mineral composition of supstrates, in order to, understand its nature, and prevent negative influences that can come with usement of mineral fertilizers. On the Figure 1 is shown mineral analy- sis of loess samples. Determination and constatation of presence of certain minerals is given on the basis of characteristics values for every one of minerals in units (Angstrem $\AA$ ).

On the Figure 1:

- with blue color is presented dry sample of loess,

- with green color is presented saturated sample of etilenglicol,

- with red color is presented process of heating until red sample at $550^{\circ} \mathrm{C}$.

Figure 1 presents following phenomen minerals of clay:

- 14 - $15 \AA$, are identified Vermikulit and Smektiti,

- $10 \AA$, identified Ilit,

- $7 \AA$, is identified Kaolinit.

Some minerals have expressed characteristics of adsorption, as it is the case with some minerals of clay, so the soil with greater quantity of clay is from the side of plants bind in soil, while only smaller part gets to underneath-water. However, in case of sandy soil, that have not so big capability of adsorbtion, we have to be carefull while washing out not adopted nourishments on the nitrate basis, because their supstrate can come to underneath

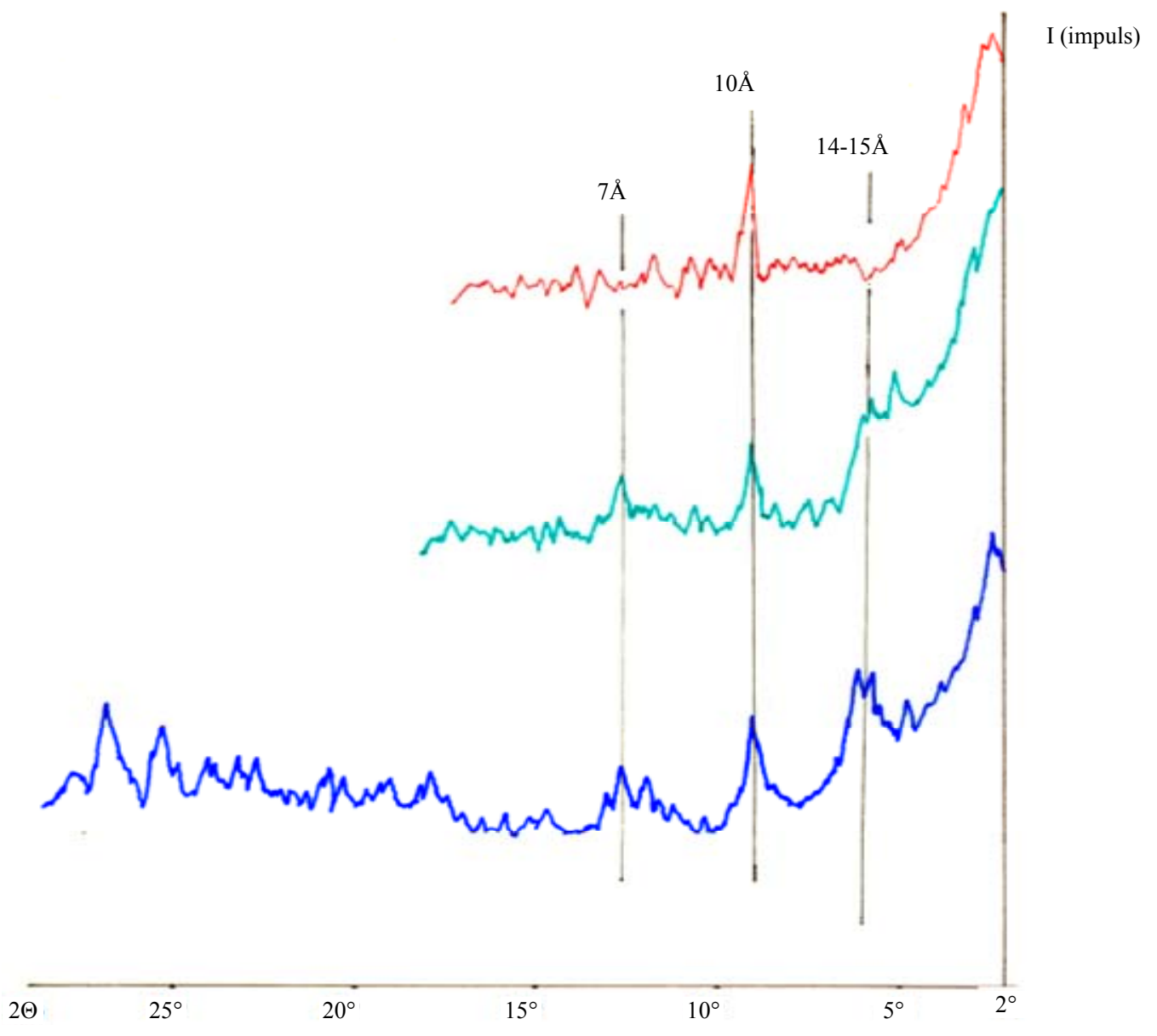

Figure 1. X-Ray minerological analysis of loess. 
water, that negativelly influence on enviroment. Two different kind o experiments of sorption characteristics of soil were conducted. Examining sorbing were done as difference of concentration of nitrate ion in solution before and after passing through solution as well as extracting from soil after wetting with solution of certain concentration of nitrate. Those experiments were:

1) Experiment of sequential depths. Flow of conducting the experiment gets like this: we fill the column with sample until certain height $(10,20,40 \mathrm{~cm})$. Then we pass standard nitrate solution and catch passed liquid for the purpose of further measurement of concentration of nitrate ion.

2) Experiment of extraction depths - we were examining quntity of anion is their stay in soil. Experiment then follows in this way: column fill up with sample until the height of $1 \mathrm{~m}$. Then, we pass standard solution of nitrat and extraht the soil on the height of 10, 20 and $40 \mathrm{~cm}$, and determine concentration of nitrate.

And in experiment of sequential depths and also in extraction depths were used simulation of nitrate solution movement (simulation of atmospheric). In both cases was dealt with two ways of flow:

1) Continuous (regulated) flow and

2) Complete flow (without regulation).

Continuous flow presents in advance defined system with regulation of liquid volumen that passes through certain mass of sample. Firm sample completely gets wet with solution, and concentrations that are measured can be considered as to bi in equilibrium. This experiment simulated complete wetting of soil in longer time interval. It could be compared with method of watering soil "drop by drop". The very same experiment conducts on next way: Columns are filled with washed out sand and loess until the height of 10, 20, $40 \mathrm{~cm}$. This pillar height corresponds to precisely defined mass of sand and loess. On the top of column is reservoir with tap, where we adjust speed of flow of 3 drops (volume of drop $0.05 \mathrm{ml}$ ) per minute. The tap on the bottom of column is opened. Underneath of column is placed erlenmaier in which is gathered liquid that pass through column. In reservoir we pour $100 \mathrm{ml}$ of deionezed water and we measure time needed for flow of that quantity of water through column. When all quantity of water flows through, then we start to measure time with stopwatch, and the volume of eluata and we determine the degree of wetting. When the sand in column dries out, the process is repeating only we instead of deionized water put $100 \mathrm{ml}$ solution of $\mathrm{NaNO}_{3}$. After flowing out of complete quantity of solution $\mathrm{NaNO}_{3}$, we mark sample and we are saving it for the next analysis. By regime "complete flow" the only regulation of flowing out is indeed permeability of pillar of firm sample. Measured concentration can be deemed as in equilibrium. In real life conditions, measured concen- trations can not deemed to be in equilibrium. In real conditions regime "complete flow" could maybe been characterized as the "possibility of washing out of material". This experiment should simulate shorter time of wetting substrates. Columns are filled with dry sand or loess to already mentioned heights of pillar of $10 \mathrm{~cm}, 20 \mathrm{~cm}$ and $40 \mathrm{~cm}$. Underneath of column is placed the erlenmaier in which we catch the liquid that flows through column. We pour in reservoir $100 \mathrm{ml}$ deionized water, and then we measure time needed for that quantity of water flow out through column. When all qantity of water flow through column, we write down the time of flowing out and then measure volume of passed water. When sand in column dries out we repeat that process, only instead of deionezed water we put $100 \mathrm{ml}$ of $\mathrm{NaNO}_{3}$ solution. After flowing out of all quantity of $\mathrm{NaNO}_{3}$ solution, we write down time of flowing out and mark the sample and save it for further analysis. The same act we repeat and for loess analysis. Gained concentrations of aniona in demi water used for making solution in basic solution are cited in basic Table 2 .

Concentration of passed nitrates in eluate is biggest when the height of pillar sample is $10 \mathrm{~cm}$ that is the consequence of making equilibrium in column that is because of comming to new quantity of nitrate solution, constantly moving in direction of washing out. When we compare method of complete flowing out and method of continuous flow we see (Table 3.) the difference in time of nitrate sorbing as well as the difference in concentrations of retained nitrates.

Washing out nitrates from soil comes as consequence of their solutability and because the soil has not capability to bond them higher, eighter chemically eighter phisically. Nitrates do not grade unsolutable salts, with neighter cation from soil, and on the surface of coloid particles they can not to adsorb. On the basis of this we can conclude that nitrate iones do not bond in soil, and also by flowing out of water iones of nitrate are washing out. As climate is more humid (with more rainfalls) or we use drenching out, so the bigger is the washing out.

Table 2. Composition of ions in demi water and in basic solution of nitrates (in further text this solution was used for analysis).

\begin{tabular}{cccc}
\hline & Florides & $\begin{array}{c}\text { Demineralized } \\
\text { water }\end{array}$ & $\begin{array}{c}\text { Basic nitrate } \\
\text { solution }\end{array}$ \\
\hline & Chlorides & 0.025 & 0.02 \\
Concentration & Nitrites & - & 0.63 \\
of anion (mg/L) & Nitrates & - & - \\
& Phosphats & - & 39.64 \\
\hline
\end{tabular}

*Border for detection for chlorides is $10 \mu \mathrm{g} / \mathrm{L}$. 
Table 3. Comparing results of time of sorbing and concentration of retained nitrates for sand by complete and continuous flow.

\begin{tabular}{cccc}
\hline Sand & $\begin{array}{c}\text { Depth } \\
\mathbf{1 0}(\mathbf{c m})\end{array}$ & $\begin{array}{c}\text { Depth } \\
\text { 20 (cm) }\end{array}$ & $\begin{array}{c}\text { Depth } \\
\mathbf{4 0}(\mathbf{c m})\end{array}$ \\
\hline Balanced weight (g) & 15 & 30 & 60 \\
& Continuous flow & & \\
Time (min) & 100 & 140 & 190 \\
Nitrates (mg/kg) & 5.4 & 10.96 & 22.03 \\
& Complete flow & & \\
Time (min) & 120 & 160 & 200 \\
Nitrates (mg/kg) & 8.50 & 18.23 & 34.06 \\
\hline
\end{tabular}

When it is about soil, the harder the mechanical composition (more clay), the weaker is soil in passing water and then it comes to smaller washing out and bigger retaining nitrates, because in soil dominate smaller pores and water is moving slower. Loess contains more dust and clay, smaller porosity of soil, and the filtrating is slower then at sandy surfaces. Because of that quantity of nitrate fertilizers that are giving on sandy soil is less then on the soil of harder mechanical composition. From the Figure 2, we can see correlation between height of pillar of sand (loess) and certain quantity of nitrates, which is pointing us that bigger heights of pillar in this sample would not importantly change retaining of nitrates. Sorbing of nitrates is bigger on loess then on sand, respectively concentration of nitrates after passing solution are always smaller in solution that has passed through loess then in solution passed through sand.

On the Figure 2, the upper gives correlation between of time of and height of pillar of sand/loess, and the lower picture shows relations between heights of pillars of sand/loess and nitrate concentration.

\section{DISCUSSION AND CONCLUSION}

For the purpose of this investigation,we have choosen as supstrate sand and loess, because of great difference in characteristics - permeability and porosity that is caused by granulometric composition of the same. One of the most important reason is that the fertile soil on which intensive agriculutural production is taking place, is based on loess, and that causes constant maleiration of soil by introducing artificial fertilizers. Solutability of $\mathrm{NaNO}_{3}$ is big, so the fertilizers go over in solution when in soil is enough water. In case that the quantity of water in soil is big, and that their prevail descedent costs, there is present danger that nitrate will be washed out and in deeper layers. For this reason we need to evade adding great quantity of $\mathrm{NaNO}_{3}$, as well as the other fertilizers that contain nitrogen in the form of nitrate.Washing out
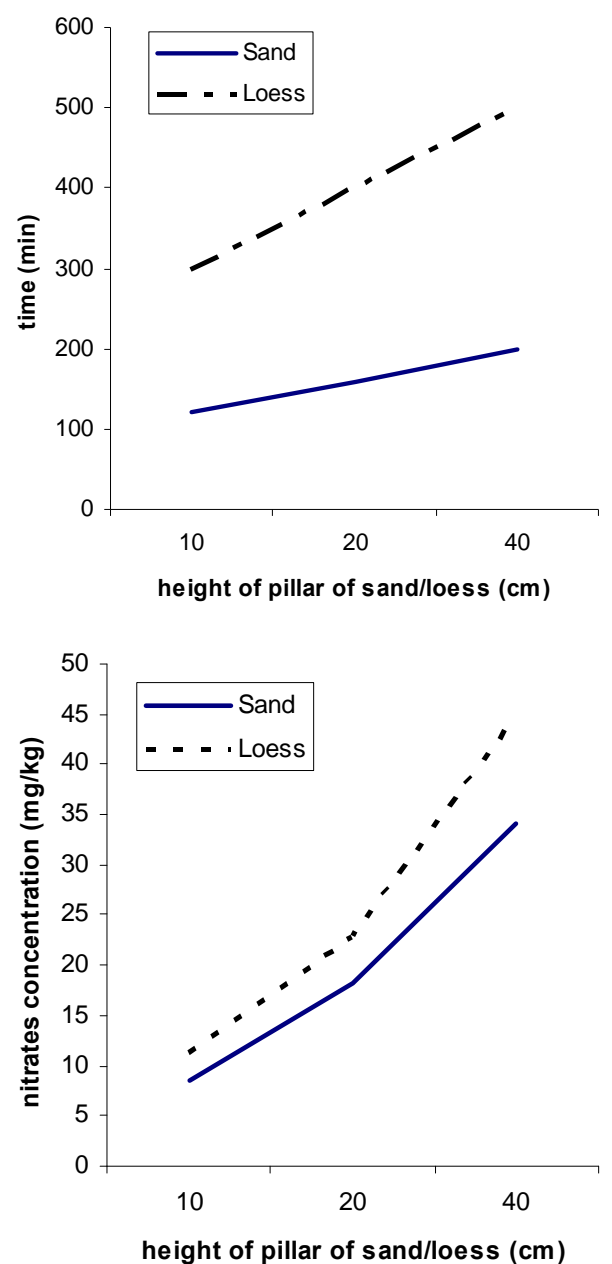

Figure 2. Correlation between height of pillar of sand (loess) and quantity of nitrates.

nitrates from soil comes as a result of their solutability and because of the fact that soil has not the capability to bond them chemically or phisically-chemically. Nitrates do not build unsolutable salts with neighter cation of soil, and on the surface of coloid particles they can not to adsorb. On the basis of this, we can conclude that $\mathrm{NO}_{3}^{-}$ ion does not bond in soil, and when the water is presented, it is washing out because the climate is more humid (more rainfalls or we use irrigation) and this causes greater washing out and smaller retaining nitrates in sandy soil, in comparison with loess where retaining is greater, that is confirmed with experiments. When it is about soil, the harder mechanical composition is (more clay), the smaller will be the capability of soil to pass water and it comes to smaller washing out and greater retaining, because in soil dominate smaller pores and water moves slowly. Loess contains more dust and clay, the porosity of soil is smaller, so filtering here is slower than sanding. Because of that are, for example quantities of nitrate fertilizers that are given on sandy soil in one move smaller than on soil of harder mechanical compo- 
sition.

\section{REFERENCES}

[1] Implementation of Council Directive 91/676/EEC Concerning the Protection of Waters against Pollution Caused by Nitrates from Agricultural Sources, Luxembourg, 2002.
[2] Bergstrom, L. and Johansson, R. (1991) Leaching of nitrate from monolith lysimeters of different types of agricultural soils. Journal of Environmental Quality, 20, 801807.

[3] Al-Darby, A. and Abdel-Nasser, G. (2006) Nitrate leaching through unsaturated soil columns: Comparison between numerical and analytical solutions. Journal of Applied Sciences, 6, 735-743. 